\title{
Applying CPM-GOMS to Two-handed Korean Text Entry Task on Mobile Phone
}

\author{
Jiseung Back, Rohae Myung \\ Department of Industrial Management Engineering, Korea University, Seoul, 136-713
}

\begin{abstract}
In this study, we employ CPM-GOMS analysis for explaining physical and cognitive processes and for quantitatively predicting when users are typing Korean text messages on mobile phones using both hands. First, we observe the behaviors of 10 subjects, when the subjects enter keypads with both hands. Then, basing upon MHP, we categorize the behaviors into perceptual, cognitive, motor operators, and then we analyze those operators. After that, we use the critical paths to model two task sentences. Also, we used Fitts' law method which was applied many times to predict text entering time on mobile phone to compare with the results of our CPM-GOMS model. We followed Lee's (2008) method that is well suited for text entry task using both hands and calculate total task time for each task sentences. For the sake of comparison between the actual data and the results predicted from our CPM-GOMS model, we empirically tested 10 subjects and concluded that there were no significant differences between the predicted values and the actual data. With the CPM-GOMS model, we can observe the human information processes composed on the physical and cognitive processes. Also we verified that the CPM-GOMS model can be well applied to predict the users' performance when they input text messages on mobile phones using both hands by comparing the predicted total task time with the real execution time.
\end{abstract}

Keywords: Human Performance Modeling, Cognitive Architecture, CPM-GOMS, Fitts' Law

\section{1. 서 론}

전화 송, 수신의 기능만을 담당하던 모바일 폰이 오늘날 사용이 증가되고 인터넷과 결합을 함으로써 모바일 폰 사용 자에게 다양한 컨텐츠를 제공할 수 있게 되었다(Bergman, 2000). 최근에는 네트워크 커뮤니케이션을 통해 온라인과 오프라인 영역의 경계가 사라지면서 우리는 이전보다 훨씬 많은 문자 메시지를 전송하게 되었다(정부용, 2006). 국내 대학생들을 대상으로 단문 서비스 사용 실태를 조사한 결과, $100 \%$ 에 가까운 숫자가 서비스를 이용하고 있고, $70 \%$ 이 상이 매일 단문 서비스를 사용하고 있는 것으로 나타나 있 다(Choi, 2000).

하지만 기본적으로 모바일 폰의 문자 입력은 좁은 가용
공간으로 인해 사용자의 인지 부하를 증가 시킨다(김상환 등, 2002). 모바일 폰의 사용 시 가장 불편함이 유발되는 작업을 설문조사를 통해 연구한 결과 문자 입력 작업으로 나타난 것(기도형, 2006)으로 미루어 보아 한글 입력 키패 드에 대한 평가와 사용자의 수행력을 높일 수 있는 새로운 키패드의 필요성이 증가했다.

기존 연구에서는 한 손 입력 과정에 대한 경험적이고 이론적인 연구가 다양하게 이루어져 왔다. 키패드 위에서 손의 이동 시간(MT)은 Fitts' law에 기반하여 정량적으로 예측할 수 있는데, Fitts' law는 물리적인 인터페이스의 평 가를 위해 HCI(Human Computer Interaction) 영역에서 인간의 과제 수행 시간을 예측하기 위한 강력한 도구로 적용되어 왔다(김상환 등, 2002). Fitts' law를 이용하여 Silfverberg et al. (2000)은 영문 텍스트 입력에 대한 이

Corresponding Author: Rohae Myung. Department of Industrial Management Engineering, Korea University, Seoul, 136-713.

Phone: 02-3290-3392, e-mail: rmyung@korea.ac.kr

Copyright@2011 by Ergonomics Society of Korea (pISSN:1229-1684 eISSN:2093-8462). All rights reserved. 
동 시간 예측 모델을 모바일 폰에의 손의 이동거리(D: Distance) 와 타겟의 폭(W: Width)의 관계를 이용하여 아 래 식 1 과 같이 나타내었고,

$$
\mathrm{MT}_{\text {English }}=176+64 \log _{2}(\mathrm{D} / \mathrm{S}+1)
$$

김상환 등(2002)은 한글 입력에 대한 이동 시간 예측 모델을 다음 식 2 와 같이 나타내었다.

$$
\mathrm{MT}_{\text {Koream }}=203+48 \log _{2}(\mathrm{D} / \mathrm{S}+0.5)
$$

하지만 모바일 폰의 문자 메시지, 멀티미디어 메시지, 웹 서핑의 사용이 증가함에 따라 많은 모바일 폰 사용자들은 문자를 입력하기 위해 양 손을 이용하게 되었다. 따라서 모 바일 폰 사용자들의 행태 변화 양상에 따라 양 손 입력 방 식에 대한 연구가 점차 필요하게 되었다. MacKenzie et al. (2002)은 양 손의 교차 입력 작업이 반복되어 일어날 때 입력 시간은 한 손을 이용한 입력 시간의 $1 / 2$ 로 된다는 일 정한 규칙을 발견하였으며, 이주우 등(2008)은 이러한 규 칙을 이용하여 Fitts' law에 기반하여 모바일 폰에서의 문자 입력 시 양 손 입력 행태를 반영한 수학적 예측 모델을 제 시하였다. 하지만 이들 연구는 문자 입력 과제에 대한 사용 자의 정신적인 과정을 배제하고 손의 물리적인 이동 시간만 을 고려하였기 때문에 사용자의 입력 행태를 분석하고 예측 하는데 한계가 있다.

이러한 한계를 극복하기 위하여 Card et al.(1983)이 'The psychology of Human Computer Interaction'에서 소개한 인지 모델(cognitive model)을 이용해 볼 수 있다.

인지 모델은 인간의 지각, 인지, 행위 과정을 예측하기 위 해 고안된 인지 아키텍쳐(cognitive architecture)에 기반 한 것으로 특정 과제에 대한 수행 시간, 에러율, 학습률 등 여러 정량적 답을 세밀하게 알아 낼 수 있으며 특정 인터페 이스에서 사용자가 주어진 과제를 어떻게 성취할 수 있는지 에 대한 예측을 할 수 있게 한다.

지금까지 인지 모델은 많은 연구자들을 통해 다양한 방 법으로 연구가 이루어졌으며, 대표적인 인지 모델의 종류 로는 GOMS 모델(Card et al., 1983), ACT-R (Anderson, 1983), Soar(Newell, 1990), EPIC(Kieras and Meyer, 1996 ) 등이 있다. ACT-R, SOAR, EPIC은 프로덕션 시스 템을 기반한 모델로서, 아키텍쳐의 크기가 크고 복잡하기 때문에 이들을 효율적으로 사용하기 위해서 디자이너로부터 전문성과 많은 작업을 요구한다(Byrne, 2003).

반면 GOMS는 인지 · 행위 모형의 하나로서 $\mathrm{HCI}$ 분야 에서 넓은 이론적 배경을 바탕으로 인지 과정을 분석하고 (John et al., 1996a), 목표 과제와 상태에 대한 사용자의
행동과 수행을 예측할 수 있다(Kieras, 2007). John et al. (1996b)은 모델링 과정과 특징에 따라 CMN-GOMS, KLM, NGOMSL, CPM-GOMS의 4가지 GOMS modeling 기법 을 소개하였다. 이 4가지 기법들 모두 목표(Goals), 조작자 (Operators), 방법(Methods), 선택 규칙 (Selection Rules) 의 관점에서 사용자가 제품을 사용할 때 어떻게 사용하는 지에 대한 사람의 행동과 인지 과정을 분석한다. 한편 오퍼 레이터 수행에 대한 가정에 따라 크게 둘로 구분된다. 먼저 $\mathrm{CMN}-\mathrm{GOMS}, \mathrm{KLM}, \mathrm{NGOMSL}$ 는 모든 오퍼레이터가 순 차적으로 발생한다고 가정하여 과제를 분석할 때 시간에 따라 하나의 오퍼레이터가 처리된 후 다음 오퍼레이터가 순차적으로 수행된다고 보았으며, 이와 대조적으로 CPM$\mathrm{GOMS}$ 는 오퍼레이터의 병렬적 수행을 허용하여 동시에 여 러 개의 오퍼레이터를 처리하는 과정을 분석할 수 있다.

본 연구에서 살펴보는 모바일 폰에서의 문자 입력은 한 손이 아닌 양 손을 사용하기 때문에 양 손의 움직임에 대한 교차 작용과 동시에 이들의 움직임을 지각하고 인지하는 정 신적인 과정이 병렬적으로 이루어질 것이다. 따라서 이러한 병렬적 작업을 분석하기 위해서 GOMS의 4 가지 기법 중 $\mathrm{CPM}-\mathrm{GOMS}$ 를 이용하였다.

CPM-GOMS는 MHP (The Model Human Processor) 와 밀접하게 연결되어 있는데(Card et al., 1983), MHP는 인간의 정보 처리 시스템을 설명하기 위해 프로세서 간의 상호 연결과 일반적인 오퍼레이션의 원리를 기술하는 것으 로서, 다양한 메모리와 프로세스, 그리고 그들의 특징을 대 표하는 시스템으로 구성되어 있다. CPM-GOMS는 critical path method를 이용하여 과제의 처리 과정이 순차적인지 병렬적인지 나타내주며 병렬적 과제에서 복잡한 상호 작용 을 수반하는 과제에 대하여 총 수행 시간을 분석할 수 있도 록 해준다(Gray et al., 1993). 따라서 CPM-GOMS를 이 용하면 우리는 이전의 다른 GOMS 모델이 분석하지 못했던 병렬적 처리 모델을 효과적으로 분석할 수 있다.

따라서 본 연구에서는 양 손을 이용한 모바일 폰에서의 문자 입력 과제에 대하여 지각적, 인지적, 물리적으로 사용 자 수행을 분석하기 위한 새로운 인지 모델 제시를 목적으 로 한다.

또한 기존 연구에서 제시된 양 손 입력 과제 예측을 위한 수학적 예측 모델과 비교를 통해 $\mathrm{CPM}-\mathrm{GOMS}$ 모델의 유 효성을 검증해보는 것을 목적으로 한다.

\section{2. 연구 방법}

실험에 사용된 모바일 폰 단말기는 $\mathrm{SCH}-\mathrm{B} 630$ 의 슬라 
이드 형태이며, 버튼 입력 방식으로 12 개의 전화용 버튼 $(0$ 부터 9 까지의 숫자와 \#,* 버튼) 과 10 개의 기능 버튼으로 구성되어 있다. 본 연구에서는 '0 9', '\#', '*'로 구성된, 모든 전화기에 공통으로 들어가는 버튼들을 이용하여 실험을 진 행하였다. 각 버튼의 가로 길이는 $10.1 \mathrm{~mm}$ 이고, 세로 길이 는 $5 \mathrm{~mm}$ 이며, 버튼 간의 간격은 수평, 수직 간격 모두 $1 \mathrm{~mm}$ 이다.

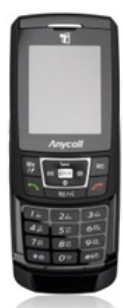

Figure 1. 연구에 사용된 모바일 폰

이주우 등(2008)의 연구에 따라 대부분의 모바일 폰 사 용자들이 Figure 2처럼 가장 왼쪽의 키 열을 왼손으로 입 력하고, 나머지 가운데 열과 가장 오른쪽 열의 키 열들을 오 른손으로 입력하는 완전 분리 형태를 보인다고 가정하였다.

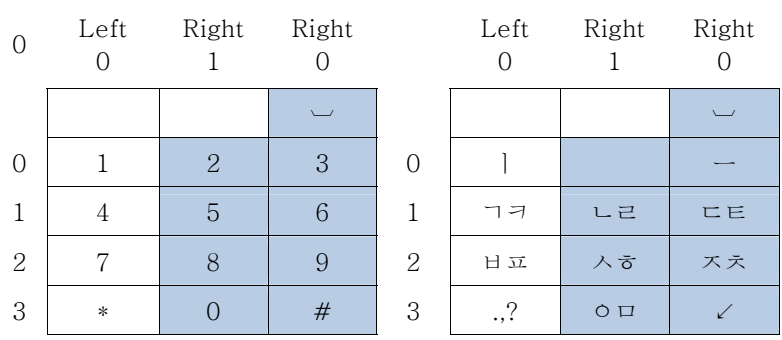

Figure 2. 버튼 조합

\section{$2.1 \mathrm{CPM}-\mathrm{GOMS}$ 모델링}

\subsection{1 오퍼레이터 산출}

문자 입력 과제에 대한 오퍼레이터를 산출하기 위해 실험 을 실시하였다. 10 명의 대학원생 학생이 피 실험자로 참여 하였으며 이들의 평균 연령은 27.2( \pm 1.23$)$ 세이다. 실험에 앞서 단말기가 피 실험자의 손에 익을 때까지 20분 이상 충분히 연습하도록 한 후, 몇 개의 문장을 주고 전술한 모바 일 폰을 사용하여 문장을 입력하게 하고 입력 과정을 비디 오카메라로 촬영하였다. 그 후 녹화한 피 실험자의 문자 입 력 과정을 $\mathrm{MHP}$ 에 기반하여 perceptual operator, cognitive operator, motor operator의 3개의 오퍼레이터로 분석하 였다.
$\mathrm{MHP}$ 오퍼레이터의 예측 시간과 목표를 달성하기 위해 이들 오퍼레이터가 어떻게 조합을 하는지에 대한 일반적인 이론은 John (1990) 과 John et al. (1989)에 기초하였다.

아래 Table 1 은 문자 입력 과제에 대한 오퍼레이터와 각 오퍼레이터를 수행하는데 걸리는 시간을 나타낸다.

Table 1. CPM-GPMS 모델링에 사용된 오퍼레이터들

\begin{tabular}{|c|c|c|}
\hline \multirow{2}{*}{$\begin{array}{l}\text { The perceptual } \\
\text { operators }\end{array}$} & Perceive(task sentence) & $290 \mathrm{~ms}$ \\
\hline & Perceive key arrangement & $100 \mathrm{~ms}$ \\
\hline \multirow{6}{*}{$\begin{array}{l}\text { The cognitive } \\
\text { operators }\end{array}$} & Initiate eye movement & $50 \mathrm{~ms}$ \\
\hline & Encoding (task sentence) & $50 \mathrm{~ms}$ \\
\hline & Spelling obtain & $50 \mathrm{~ms}$ \\
\hline & Initiate $\mathrm{R} / \mathrm{L}$-hand movement & $50 \mathrm{~ms}$ \\
\hline & Initiate eye movement & $50 \mathrm{~ms}$ \\
\hline & Confirm syllable & $50 \mathrm{~ms}$ \\
\hline \multirow{2}{*}{$\begin{array}{l}\text { The motor } \\
\text { operators }\end{array}$} & \multicolumn{2}{|c|}{$\begin{array}{l}\text { R/L-hand movement operators: Fitts' law에 } \\
\text { 따름 }\end{array}$} \\
\hline & Eye movement operator & $180 \mathrm{~ms}$ \\
\hline
\end{tabular}

본 연구에서는 이주우 등(2008)의 연구에 사용된 타켓 모바일 폰과 같은 기종을 사용하여 그의 연구에서 산출된 입력 시간 도출 공식을 이용하였다. 따라서 Fitts' law를 이 용하여 전술된 모바일 폰 단말기의 숫자 버튼을 누를 때 입 력 시간을 도출하는 공식은 다음과 같다.

$$
\operatorname{MT}(\mathrm{msec})=245+55 \log _{2}(\mathrm{~A} / \mathrm{W}+0.5)
$$

\subsubsection{CPM-GOMS 모델 수립 가정}

본 연구에서는 CPM-GOMS 모델링을 하기 앞서 선행된 실험을 통해 몇 가지 특성을 발견하고 이를 통해 모바일 폰 을 이용한 문자 입력에 관하여 몇 가지 규칙을 정의하였다.

피 실험자가 입력해야 할 과제 문장을 듣게 되면 cognitive operator를 통해 문장이 몇 개의 chunk로 나누어 질 수 있는지 결정한다. 그런 다음 입력할 문장에 대한 철자를 기 억해 내고 철자를 구성하는데 필요한 문자 요소들의 조합 방법에 대한 정보를 얻게 되며 이 두 과정은 동시에 일어나 게 된다. Chunk의 결정은 문장을 가장 작은 의미 단계로 나 누는 것으로 가장 작은 의미 단위가 하나의 chunk가 된다.

버튼 입력 방식은 전문가의 경우 각 키의 위치와 배열에 대한 정보가 장기 기억에 저장되어 있기 때문에 문자를 입 력할 때 마다 키 배열을 눈으로 확인하지 않는 것으로 나타 났다. 따라서 본 연구에서는 피 실험자가 입력해야 할 과제 문장을 듣고 그 문장의 chunk 개수를 결정하는 과정과 눈 을 움직여 전체적인 키의 배열을 확인하는 과정이 동시에 


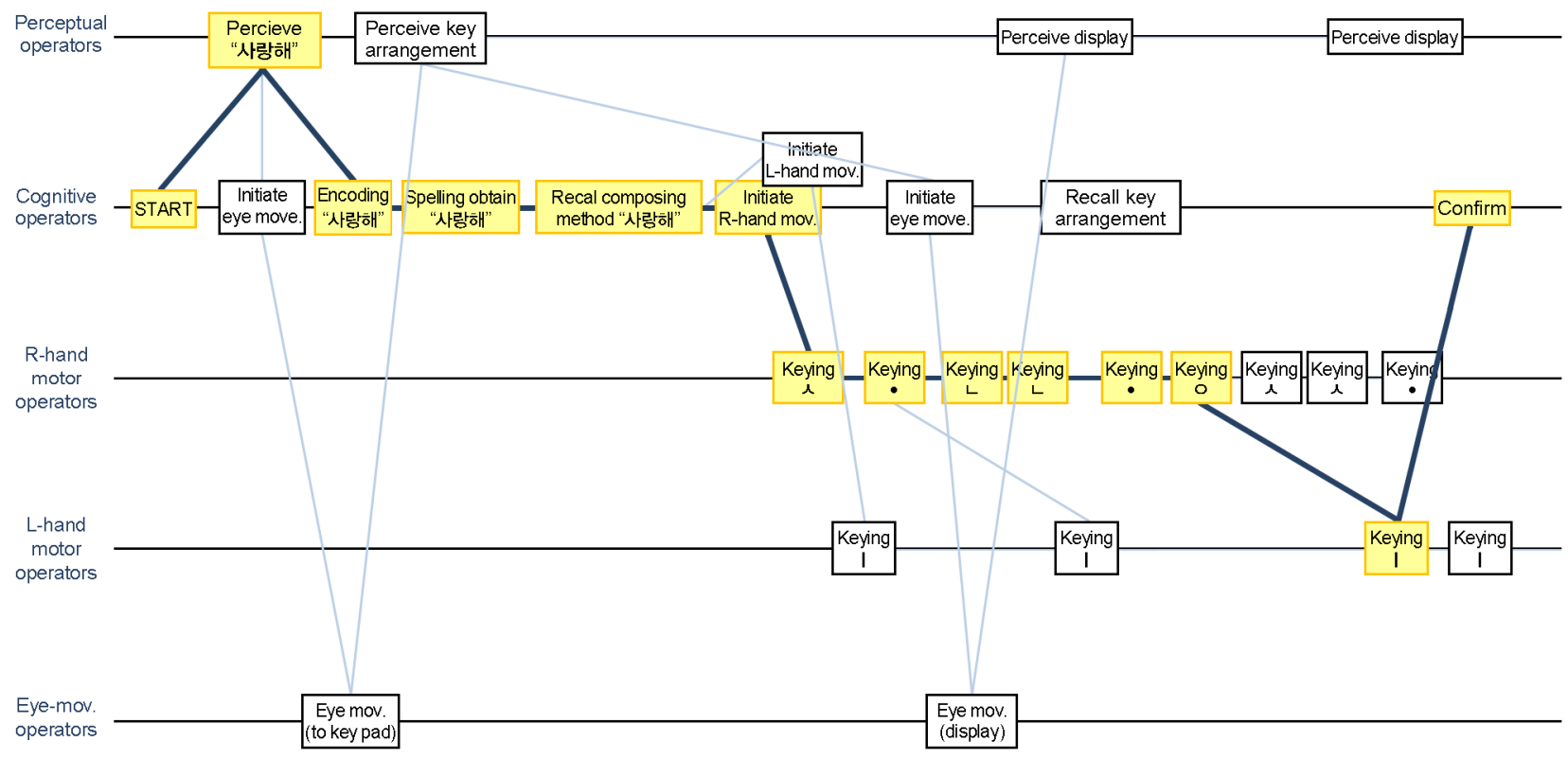

Figure 3. 과제 문장 1 "사랑해"에 대한 Critical path 결과

일어나도록 설정하였다. 그 후 피 실험자는 눈을 버튼에서 디스플레이로 이동시켜 문장을 입력하는 동안 입력되는 문 자를 확인하는 과정을 수행하는 것으로 가정하였다. 또한 과 제 문장을 모두 입력하고 난 후 자신이 입력한 문장이 옳은 지 확인하기 위한 시각 과정을 살펴볼 수 있었는데 이 과정 은 과제 처리 단계의 마지막에 이루어지도록 설정하였다.

눈으로 키의 위치와 배열을 인지한 사용자는 왼손과 오른 손을 움직여 문장을 입력하기 위한 준비를 하는데 이때 왼 손과 오른손의 준비 단계는 cognitive operator에서 동시에 일어나며 이 과정에서 어떤 손을 먼저 움직여 문자를 입력 하고 어떤 순서로 입력하여야 하는가에 대한 정보 인지 과 정이 포함된다.

본 연구에서는 Myung(2004) 실험에 사용된 문장들 중 사용자들이 가장 많이 사용하는 문장인 '사랑해'와 '늦을 것 같으니까 조금만 기다려'를 이용하였다. 이들 문장을 위에서 언급한 가정과 Fitts' law를 이용하여 도출한 입력 시간을 통해 CPM-GOMS 모델을 생성하였다.

\subsection{Fitts' law를 이용한 수학적 예측 모델 수립}

김상환 등(2002)은 Fitts' law를 이용하여 모바일 폰에 서 한 손을 이용한 문자 입력 시간을 예측하였고, 이주우 등 (2008)은 양 손을 이용한 문자 입력 시간을 예측하였다. 본 연구에서는 이주우 등 (2008)의 연구에서 사용한 양 손을 이용한 문자 입력 시간 예측하기 위한 수학적 모델을 이용 하여 과제 문장에 대해 예측되는 총 입력 시간을 구하였다.

\subsection{Empirical test}

CPM-GOMS 모델을 통해 예측된 수행 시간과 문자 입 력 과정이 실제 모바일 폰 사용자의 양 손을 이용한 과제 수행 결과와 얼마나 일치하는지 확인하기 위해 평균 나이는 26( \pm 1.5 )세인 10 명 (남자 7명, 여자 3명)의 피 실험자를 통해 살펴보았다. 이들 모두 오른손 잡이이고, 버튼 입력 방 식의 모바일 폰 단말기를 1 년 이상 사용하였으며 하루에 평균 3 번 이상 문자 메시지를 작성했다. 동일한 실험 환경 을 위해 과제 문장을 미리 녹음을 하여 피 실험자에게 들려 주었으며 한 문장이 모두 제시된 후 입력을 시작하도록 하 였다. 그리고 각 과제 문장의 입력 시간은 문장 제시가 끝난 직후부터 피 실험자가 문장을 모두 입력하고 '확인' 버튼을 누를 때까지의 시간을 문장 입력 시간으로 설정하였다.

\section{3. 연구 결과}

\section{$3.1 \mathrm{CPM}-\mathrm{GOMS}$ 모델링 결과}

모바일 폰 단말기에서 양 손을 이용하여 문자를 입력하는 과제에 대한 전체 과정은 schedule chart로 나타낼 수 있 으며, Figure 3 은 본 연구에 사용된 두 개의 과제 문장 중 문장 1 , '사랑해'를 schedule chart로 나타낸 것으로서 전체 문장을 입력하기 위한 피실험자의 인지 과정과 물리적인 운 동 과정을 병렬적으로 나타낼 수 있다. 
모델링을 통해 세 가지 특징을 찾아볼 수 있었는데, 만약 같은 손으로 버튼을 두 번 이상 누르게 되는 경우 마지막 버튼을 누르기 전에 반대편 손이 입력 준비를 한 뒤 마지막 버튼의 입력이 완료된 후 곧바로 입력을 할 수 있다. 예를 들어 문장 2에서 "늦을 것 같으니까 조금만 기다려"에서 '으니까'를 입력할 때 왼손으로 'O', '-', 'ㄴ'를 입력한 뒤 ' l', 'ㄱ'는 오른손으로 입력하게 되는데 왼손으로 'ㄴ'의 입 력이 끝나기 전에 오른손으로'।'를 입력하도록 준비시킨 후 'ㄴ' 입력이 끝난 후 시간적 지체 없이 바로 입력할 수 있게 된다.

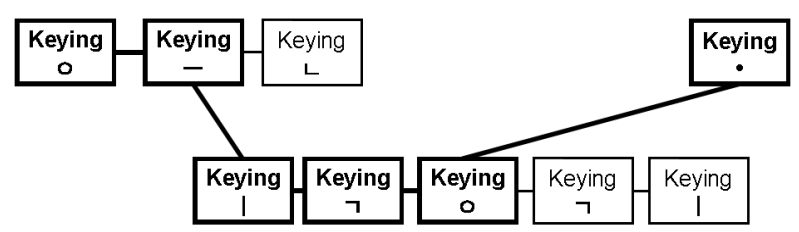

Figure 4. CPM-GOMS 모델링 결과 나타난 특징(1)

한편 입력하여야 할 과제 문장이 길어 chunk의 수가 2개 이상이 될 경우, 첫 번째 chunk의 문자 입력을 완료하기 전 에 다음으로 입력하여야 할 chunk의 철자와 문장 요소들의 조합 방법에 대한 정보를 기억해내는 과정이 일어나게 된다. 따라서 선행된 chunk의 입력이 끝나고 바로 다음 chunk 의 입력이 이루어지게 된다. '늦을 것 같으니까'는 '늦을 것' 과 '같으니까'의 chunk로 나뉘어지는데, 선행되는 '늦을 것' 의 입력이 완료되기 전에 '같으니까'를 입력하는데 필요한 철자들과 이들의 조합 방법에 대한 정보를 얻게 된다. 이로 써 앞선 chunk의 입력이 완료되면 바로 다음에 이어지는 chunk의 문자를 입력할 수 있게 되는 것이다.

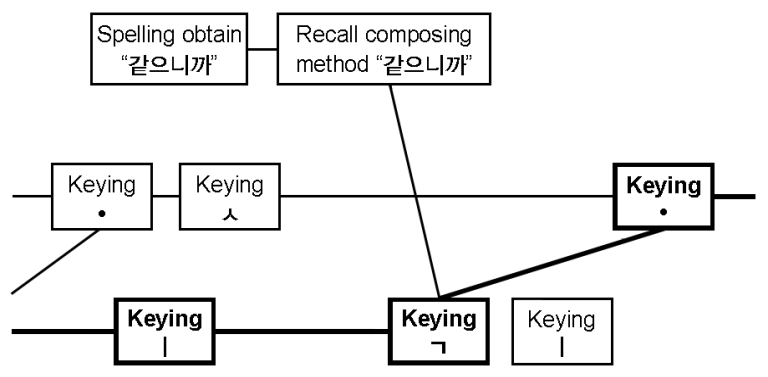

Figure 5. CPM-GOMS 모델링 결과 나타난 특징(2)

마지막으로 과제 수행에 걸리는 총 수행 시간은 마지막 철자를 입력하는 손이 아니라 전체 과제 문장을 모두 입력한 뒤 수행이 올바른지 확인하는 인지 과정에 영향을 주는 손 에 의해 결정된다. Figure 6에서 확인할 수 있듯이 가장 마
지막 버튼을 입력한 왼손이 아닌 initiate-eye-movement 오퍼레이터에 영향을 준 오른손의 버튼 입력이 총 수행시간 을 결정하는 critical path에 연결되어 있다.

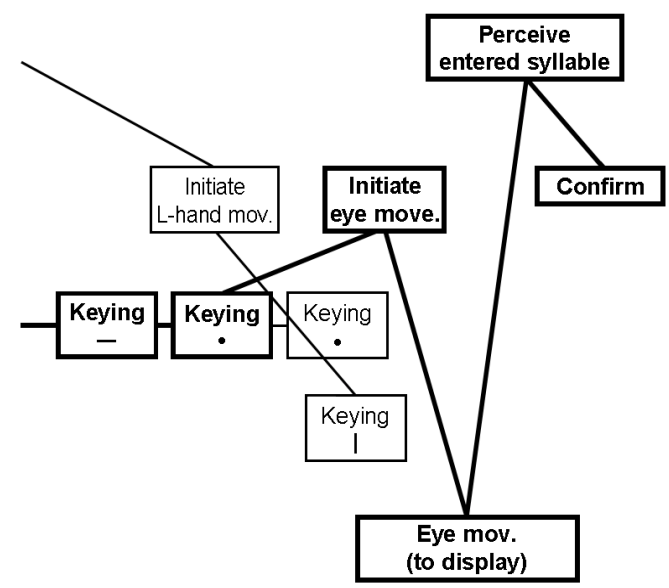

Figure 6. CPM-GOMS 모델링 결과 나타난 특징(3)

또한 CPM-GOMS 모델의 critical path를 통해 우리는 과제에 대한 총 수행 시간을 예측해 볼 수 있다. $\mathrm{CPM}-$ GOMS 모델링 결과 문장 1 '사랑해'의 경우 $2,326 \mathrm{msec}$, 문장 2 '늦을 것 같으니까 조금만 기다려'의 경우 12,497 $\mathrm{msec}$ 로 입력 시간이 예측되었다.

각 문장 별 피 실험자의 과제 문장에 따른 평균 입력 시 간은 문장 1 '사랑해'의 경우 2,278 ( \pm 130$) \mathrm{msec}$, 문장 2 '늦을 것 같으니까 조금만 기다려'의 경우 12,630 ( \pm 180 ) $\mathrm{msec}$ 로 나타났다.

Table 2. CPM-GOMS 모델링 결과와 실제 수행시간 비교

\begin{tabular}{c|c|c|c}
\hline & $\begin{array}{c}\text { 예측 시간 } \\
(\mathrm{msec})\end{array}$ & $\begin{array}{c}\text { 수행 시간 } \\
(\mathrm{msec})\end{array}$ & $\begin{array}{c}\text { 오차 } \\
(\mathrm{msec})\end{array}$ \\
\hline 문장 1 & 2,326 & $2,278( \pm 130)$ & 48 \\
\hline 문장 2 & 12,497 & $12,630( \pm 180)$ & 133 \\
\hline
\end{tabular}

$\mathrm{CPM}-\mathrm{GOMS}$ 모델을 통해 예측한 값과 실제 실험 결과 값은 문장 1 과 2 에서 각각 $48 \mathrm{msec}, 133 \mathrm{msec}$ 의 차이를 보이고 있으며 이들 간에 통계적으로 유의한 차이가 있는지 살펴보기 위해 $\mathrm{t}$-test를 실시하였다. 그 결과 문장 1 의 $p$ value는 0.7167 , 문장 2의 $p$-value는 0.6528 로 통계적으 로 유의한 차이가 없음을 알 수 있었다. 따라서 모바일 폰 에서의 양 손 입력 수행 시간 예측은 $\mathrm{CPM}-\mathrm{GOMS}$ 모델에 의해 잘 예측되었다고 볼 수 있다. 


\subsection{Fitts' law를 이용한 수학적 예측 모델 수립 결과}

이주우 등(2008)이 제시한 수학적 예측 모델을 이용하여 본 연구의 과제 문장에 대한 입력 시간을 예측해 본 결과, 문장 1 '사랑해'를 입력할 경우 2,260msec, 문장 2 '늦을 것 같으니까 조금만 기다려'를 입력할 경우 $12,440 \mathrm{msec}$ 의 시간이 걸릴 것으로 예측되었다.

두 가지 모델을 통한 예측 결과를 10 명의 피 실험자의 각각의 수행 시간과 비교하여 보았다. 아래 Figure 7과 8은 각 피 실험자의 수행 결과에 대한 오차율을 구한 것으로, 과 제 문장 1 의 경우 Figure 7 과 같이 $\mathrm{CPM}-\mathrm{GOMS}$ 모델 결 과보다 수학적 예측 모델의 결과의 오차율이 비슷하게 나타 나고 있다.

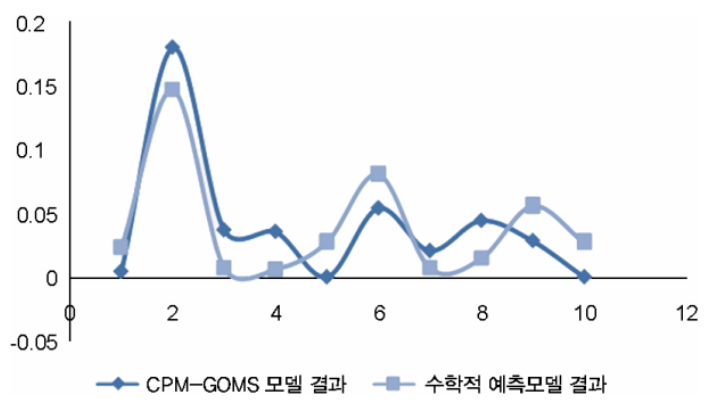

Figure 7. 문장 1 에 대한 두 모델링 결과와 수행 시간과의 오차율

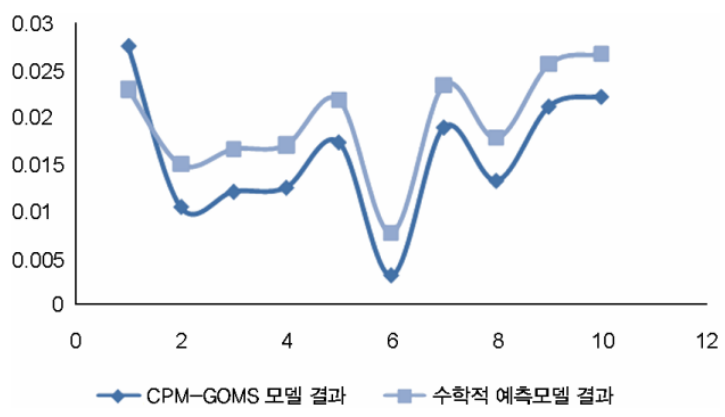

Figure 8. 문장 2에 대한 두 모델링 결과와 수행 시간과의 오차율

하지만 과제 문장 2의 경우 $\mathrm{CPM}-\mathrm{GOMS}$ 모델 결과보다 수학적 예측 모델의 결과 보다 휠씬 작은 오차율을 보이고 있는 것으로 확인되었다. 이를 통해 문장의 길이가 길어지면 $\mathrm{CPM}-\mathrm{GOMS}$ 모델을 통한 예측이 훨씬 효과적이라는 것을 알 수 있다.

\section{4. 토 의}

본 연구에서는 모바일 폰에서의 한글 입력 시 양 손 입력 행태를 $\mathrm{CPM}-\mathrm{GOMS}$ 를 이용하여 분석해 보았다.

오늘날 스마트 폰이 급속도로 발달하면서 음성 통화의 기 능만을 담당하였던 모바일 폰의 기능이 변화함에 따라 숫자 입력뿐만 아니라 문자 입력 또한 중요하게 되었다. 또한 입 력해야 할 문자의 양이 증가하면서 빠른 속도의 문자 입력 이 요구됨에 따라 모바일 폰 사용자들은 양 손을 이용하여 문자를 입력하게 되었다.

이에 따라 본 연구에서는 양 손을 이용하여 모바일 폰에 서 문자를 입력하는 과정을 분석해 보고 병렬 작업에 대한 $\mathrm{CPM}-\mathrm{GOMS}$ 모델링 기법의 유효성을 검증해 보기 위함을 목적으로 하였다.

기존의 연구에서 Silfverberg et al. (2000)과 김상환 등 (2002)은 손가락의 물리적 움직임 이동 시간(MT)을 통해 모바일 폰에서 문자 입력 시간을 예측하는 공식을 제안하 였다. 하지만 이 공식은 손 움직임의 상대적인 소요 시간과 거리에 기반하기 때문에 사용자의 정신적인 정보 처리 과 정을 알아낼 수 없다. 이러한 문제를 해결하기 위해 Myung (2004)은 KLM을, Das et al.(2007)은 ACT-R을 이용하 여 모바일 폰에서 문자 입력 과제에 대한 사용자의 기본적 인 정신 과정과 총 수행 시간을 예측할 수 있었다. 하지만 이들 연구는 한 손을 사용한 문자 입력 과제에 해당되는 것으로 양 손 행태에 대한 한계를 가지고 있다.

반면 $\mathrm{CPM}-\mathrm{GOMS}$ 를 이용하면 양 손을 이용한 모바일 폰에서의 문자 입력 과제에 대하여 지각적, 인지적, 물리적 으로 사용자 수행을 세밀하게 분석해 볼 수 있다. 인간의 병렬적인 정보 처리 과정을 효과적으로 분석할 수 있는 $\mathrm{CPM}-\mathrm{GOMS}$ 를 이용하기 위하여 먼저 실제 피 실험자의 모바일 폰을 이용한 사용자의 문자 입력 행태를 $\mathrm{MHP}$ 이용 하여 분석하였다. 그 결과 2 개의 perceptual operator, 6 개 의 cognitive operator, 2 개의 motor operator로 분류할 수 있었으며 입력 과제 처리에 대한 규칙을 찾을 수 있었다. 이러한 피 실험자의 문자 입력 행태 규칙들과 기존 문헌에 기반한 가정을 토대로 schedule chart를 이용하여 모델링 하였다.

모델링 결과 모바일 폰 사용자의 문자 입력 과제 수행에 대한 정신적인 활동과 물리적인 활동의 병렬적 작용을 살펴 볼 수 있었으며 왼손과 오른손의 병렬적 움직임의 관계도 확인할 수 있었다. 또한 schedule chart의 critical path를 이용하여 문장 입력 과제에 대한 총 수행 시간을 예측할 수 있었다. $\mathrm{CPM}-\mathrm{GOMS}$ 모델링 결과를 실제 피 실험자를 통 한 실험 결과와 비교해 본 결과 유의한 차이가 나타나지 않 
는 점으로 미루어 본 연구에서 수립한 모델이 실제 모바일 폰 사용자의 양 손을 이용한 문자 입력 행태를 잘 반영하고 있다고 볼 수 있다.

또한 이주우 등(2008)의 연구에서 기존의 Fitts' law를 이용하여 수학적으로 수행 시간을 예측한 결과를 $\mathrm{CPM}-$ $\mathrm{GOMS}$ 모델링을 통한 예측 결과와 비교해 본 결과, 문장의 길이가 긴 문장일수록 $\mathrm{CPM}-\mathrm{GOMS}$ 가 훨씬 정확한 예측을 할 수 있다는 것을 알 수 있었다. 이는 수학적 예측 모델의 경우 단순히 왼손과 오른손의 교차 작용이 일어나는 구간 에서 수행시간을 절반으로 계산하기 때문에 문장을 이루고 있는 단어의 조합에 따른 특성을 제대로 반영하지 못해 과 제 문장의 선택에 따라 영향을 받게 된다. 하지만 CPMGOMS 모델의 경우 철자 입력에 대한 양 손의 움직임 특성 을 반영한 모델이기 때문에 다양한 문장에 대한 예측이 가능 할 것이다. 또한 수행시간 예측만 가능한 수학적 예측 모델 과는 달리 $\mathrm{CPM}-\mathrm{GOMS}$ 모델은 과제 수행에 대한 인간의 지각 과정, 인지 과정, 물리적인 움직임 과정의 전체적인 병 렬 과정을 모두 고려하기 때문에 모바일 폰에서의 문자 입 력에 대한 좀 더 상세한 분석이 가능하며 병렬 과정이 포함 된 다양한 인터페이스에서 적용이 가능할 것이다.

\section{5. 결 론}

본 연구에서 우리는 모바일 폰의 한글 입력에 대한 사용 자의 양손 입력 행태를 CPM-GOMS를 이용하여 분석해 보았으며 결론은 다음과 같다.

첫째, 병렬적 과제를 효과적으로 분석할 수 있는 $\mathrm{CPM-}$ $\mathrm{GOMS}$ 를 이용하여 양 손 행태가 반영된 문자 입력 과제 수 행 예측 모델을 제시하였다. 기존 연구에서는 한 손 입력에 대한 연구가 주로 이루어졌지만 모바일 폰의 사용 형태가 변화됨에 따라 양 손을 이용한 문자 입력 사용이 증가하게 되어 양 손 입력에 대한 연구가 필요하게 되었다.

한편 기존의 Fitts' law를 이용한 수학적 예측 모델은 손 의 물리적 이동 시간만을 고려하였기 때문에 수행 시간의 예측만 가능했을 뿐 입력 과정에 대한 전반적인 병렬 작용 을 분석할 수 없었다. 하지만 CPM-GOMS의 schedule chart를 이용하면 사용자의 인지적, 물리적인 과정을 효과 적으로 분석할 수 있음을 확인할 수 있었다.

둘째, $\mathrm{CPM}-\mathrm{GOMS}$ 모델을 통해 피 실험자의 전체 문자 입력 시간을 예측해 볼 수 있었다. CPM-GOMS의 critical path를 이용하여 전체 수행 시간을 예측해 볼 수 있는데 실 제 피 실험자의 수행 결과와 비교해 본 결과 예측 값이 유 효함을 확인할 수 있었다.

\section{Acknowledgements}

본 논문은 '2단계 BK21사업'의 지원을 받아 수행된 것임.

\section{References}

Anderson, J. R., The Architecture of Cognition. Cambridge, MA: Harvard University Press, 1983.

Bergman, E., Information Appliance and Beyond, Interaction Design for Consumer Products, $1^{\text {st }}$ Ed., Morgan Kaufmann Publisher, 2000.

Byrne, M. D., Cognitive Architecture, In J. Jacko \& A. Sears (Eds.), The human-computer interaction handbook: Fundamentals, evolving technologies and emerging applications. Lawrence Erlbaum Associates, Mahwah, New Jersey, 97-117, 2003.

Card, S. K., Moran, T. P. \& Newell, A., The Psychology of HumanComputer Interaction, Hillsdale, NJ: Lawrence Erlbaum Associates, Inc, 1983.

Choi, S., The Roles of Speech, Text and Images in Mobile Communication, Proceeding of the 2000 Spring Conference or ESK and International Ergonomics Symposium, 291-294, 2000.

Das, A. \& Stuerzlinger, W., A Cognitive Simulation Model for Novice Text Entry on Cell Phone Keypads, Proceedings of the European Conference on Cognitive Ergonomics (ECCE 2007), London, UK, 141-147, 2007.

Gray, W. D., John B. E. \& Atwood M. E., Project Ernestine: Validating a GOMS Analysis for Predicting and Explaining Real-World Task Performance, Human-Computer Interaction, 8(3), 237-309, 1993.

John, B. E., Extensions of GOMS analyses to expert performance requiring perception of dynamic visual and auditory information. Proceedings of the CHI 90 Conference on Human Factors in Computing Systems, New York: ACM, 107-115, 1990.

John, B. E. \& Kieras D. E., Using GOMS for User Interface Design and Evaluation: Which Technique?, ACM Transactions on ComputerHuman Interaction, 3(4), 287-319, 1996a.

John, B. E. \& Kieras D. E., The GOMS family of user interface analysis techniques: Comparison and contrast, ACM Transactions on Computer-Human Interaction, 3(4), 320-351, 1996 b.

John, B. E. \& Newell, A., Cumulating the science of HCI: From S-R compatibility to transcription typing, Proceedings of the $\mathrm{CHI}$ '89 Conference on Human Factors in Computing Systems, New York: ACM, 109-114, 1989.

Kieras, D. E., Model-based evaluation, In J. Jacko \& A. Sears (Eds.), The Human-Computer Interaction Handbook (2nd Ed), Lawrence Erlbaum Associates, Mahwah, New Jersey, 1139-1151, 2007.

Kieras, D. E. \& Meyer, D. E., The EPIC architecture: Principles of operation, from ftp://ftp.eecs.umich.edu/people/kieras/EPICarch.ps, 1996. 
MacKenzie, I. S. \& Soukoreff, R. W., A model of two-thumb text entry. Proceedings of Graphics Interface 2002, Toronto, Canada, 117-124, 2002.

Myung, R., Keystroke-level analysis of Korean text entry methods on mobile phones. International Journal of Human-Computer Studies, $60,545-563,2004$

Newell, A., Unified theories of cognition. Cambridge, MA: Harvard University Press, 1990.

Silfverberg, M., MacKenzie, I. S. \& Korhonen P., Predicting Text Entry Speed on Mobile Phones, Proc of CHI 2000 Letters, 2(1), 9-16, 2000.

기도형., 실물 이동 전화를 이용한 한글 입력 방식의 수행도 및 선호도 평가, 대한인간공학회지, 25(3), 33-41, 2006.

김상환, 김경민, 명노해., 이동전화 한글 입력 시스템의 물리적 인터 페이스 평가에 관한 연구, 대한인간공학회지, 28(2), 193-200, 2002.

정부용., 핸드헬드 기기에서 두 손 조작을 통한 포인팅과 문자 입 력에 관한 연구, 한국과학기술원 석사학위 논문, 2006.

이주우., 양 손을 이용한 모바일 폰에서의 한글 입력 수행도 예측 모델에 대한 연구, 대한인간공학회지, 27(4), 73-83, 2008.

\section{Author listings}

Jiseung Back: jeanback@korea.ac.kr

Highest degree: BS in Science in Earth and Environmental Sciences and $\mathrm{BE}$ in Industrial Systems and Information Engineering

Areas of interest: Cognitive Ergonomics, Human Performance Modeling

\section{Rohae Myung: rmyung@korea.ac.kr}

Highest degree: Ph.D. in Industrial Engineering, Texas Tech University Position title: Professor, Department of Industrial Management Engineering, KOREA University

Areas of interest: Cognitive Engineering, HCI

Date Received : 2010-10-28

Date Revised :2010-11-30

Date Accepted : 2010-12-06 